Derecho procesal civil 
lus et Praxis, Revista de la Facultad de Derecho

N. ${ }^{4} 41,2010$

ISSN 1027-8168

pp. $165-190$

\title{
Desarrollo histórico de la justicia de paz en el Perú
}

\author{
Marianella Ledesma Narváez
}

\section{Antecedentes históricos}

En el Perú, señala Ugarte del Pino, ${ }^{1}$ la justicia a manos de los hombres y no de la divinidad se inicia con la llegada de los castellanos en el siglo XVI, quienes introdujeron la llamada justicia municipal, elegida por el pueblo, en la que los propios alcaldes impartían justicia en forma directa, si eran abogados, y a través de un tribunal conformado por dos miembros del regimiento - o sea, regidores - que fueran letrados, quienes determinaban si el fallo del juez-alcalde quedaba firme o podía ser apelado ante la Real Audiencia. Esta justicia municipal perduró hasta los inicios de la Independencia y recibió la influencia de la Constitución de Cádiz de 1812.

La justicia de paz ha estado orientada, con preferencia, al avenimiento. Como se ha señalado, dicha actividad era ejercida por el alcalde de

1 "Reseña histórica del origen y evolución de la justicia de paz en el Perú", en Temas peruanos: la justicia de paz y el pueblo. Lima: Centro de Investigaciones Judiciales de la Corte Suprema/ Fundación Friedrich Naumann, 1987, p. 20. 
cada pueblo y constituía un acto obligatorio previo a una demanda. ${ }^{2} \mathrm{La}$ Constitución de Cádiz así lo regulaba, de tal forma que quien tenía que demandar por negocios civiles o injurias debía presentarse ante el alcalde, para la conciliación. ${ }^{3}$

Con la independencia se promulgó, en 1822, el Reglamento provisional para los Tribunales de Justicia en los departamentos libres; en el ínterin se establecía el Código permanente del Estado. En este reglamento no se consideró la actividad conciliatoria del alcalde, como lo hacía la Constitución de Cádiz, pues los gobernadores, tenientes y alcaldes de los pueblos ejercían jurisdicción en sus respectivos distritos en tanto se nombraran los jueces de derecho. ${ }^{4}$

Con posterioridad, la Constitución de 1823 reafirmó la tesis de que el alcalde ejercía las funciones de juez de paz en su respectiva población; incluso, llegó a atribuir ese oficio a los regidores en poblaciones numerosas. ${ }^{5}$

La Constitución de 1826 ubica al juez de paz por primera vez dentro del capítulo destinado a la administración de justicia, a diferencia de la de 1823, que lo situó en el asignado al poder municipal. Reafirma la existencia de los jueces de paz - en cada pueblo - para las conciliaciones, y la no admisión de demanda alguna sin el agotamiento previo del requisito de la conciliación. ${ }^{6}$ En similar sentido se orientó la Constitución de $1828 .^{7}$ La regulación de la actividad conciliatoria del

Art. 284: "Sin hacer constar que se ha intentado el medio de la conciliación, no se entablará pleito alguno".

Art. 282 de la Constitución de Cádiz de 1812.

4 Incluso, se les había asignado la siguiente competencia: los alcaldes y los tenientes gobernadores conocerán de las demandas verbales civiles de menor cuantía y de las criminales sobre injurias leves y delitos menores, en las que no se debe imponer otra pena, conforme a las leyes de una moderada corrección (art. 62).

Art. 142 de la Constitución de 1823.

Art. 112 de la Constitución de 1826.

Art. 120 de la Constitución de 1828: “En cada pueblo habrá jueces de paz para las conciliaciones, sin cuyo requisito, o el de haberla intentado, no se admitirá demanda alguna civil o criminal de injurias, salvo las acciones fiscales y demás que exceptúe la ley". 
juez de paz se aleja con las Constituciones de 1836 y 1839, las que solo se refieren a estos para asignarles competencia en procesos de menor cuantía, obviando toda referencia a la actividad conciliatoria; esta última fue recogida in extenso en los reglamentos de jueces de paz de 1834, 1839 y en el actual de 1854 .

La separación de las funciones de alcalde y juez de paz no se desterró por completo, a pesar de que habían dejado de existir las juntas municipales, a las cuales pertenecían antes los jueces de paz. Esto lo decimos porque la Ley Orgánica de Municipalidades de 1834 consideraba como jueces de paz en las capitales de departamentos y de provincia a los respectivos alcaldes, sin perjuicio que atribuir la misma condición a los regidores y notables. ${ }^{8}$

La separación de ambas funciones continuó siendo motivo de reivindicación para la judicatura. Tanto el Reglamento de Jueces de Paz de 1839 como el de 1854 coincidieron en señalar que estos eran independientes de los subprefectos y gobernadores y que solo dependían de los jueces de primera instancia. ${ }^{9}$ Posteriormente, la justicia de paz ha sufrido reformas, como la consagrada por la Ley de 1900. Tanto las leyes orgánicas de 1911, 1963 y 1993 se han ocupado de regular la actividad de los jueces de paz, en igual forma como lo viene haciendo el Reglamento de Jueces de Paz de 1854. En la actualidad se mantiene un marco normativo constitucional en lo referente a la elección de jueces y a la coordinación con las autoridades de las comunidades campesinas y nativas. ${ }^{10}$

$8 \quad$ Art. 22 de la Ley Orgánica de Municipalidades de 1834. Haciendo un comentario sobre el desarrollo histórico de la justicia de paz en el Perú, Vicente Ugarte del Pino expresa: “... después de la independencia, la justicia de paz estuvo regulada por los Reglamentos y Leyes Orgánicas (...) igual que en la Ordenanza Virreinal se ha mantenido el criterio de jueces legos en derecho y jueces de paz letrados con la diferencia que no son elegidos por el pueblo durante la Justicia Virreinal, en el que al ser Juez el alcalde era elegido junto con todos los miembros del ayuntamiento o cabildo. Durante la República, como era muy largo el proceso electoral municipal, los alcaldes designados por la autoridad política pocas veces administraban justicia".

$9 \quad$ Art. 48 del Reglamento de 1839 y art. 24 del Reglamento de 1854.

$10 \quad$ Arts. 152 y 149 de la Constitución de 1993. 
Dejando a un lado estos antecedentes nacionales sobre los juzgados de paz, debe señalarse que esta es una figura que surge en los acuerdos de la Asamblea Constituyente francesa de 1789, al amparo de la ideología revolucionaria, que se inspiró en los jueces de cantón de la organización judicial holandesa. Enarbola dos objetivos: crear una justicia independiente del Poder Ejecutivo y permitir la participación del pueblo en la administración de justicia popular. Según el parecer de Puentes ${ }^{11}$ la justicia letrada se ha venido consolidando, situación que no se ha dado con la justicia popular; todo lo contrario: se ha impulsado la tecnificación o profesionalización de la justicia y la inserción de estos órganos en una estructura judicial que responda a un juez profesional en derecho, perteneciente a la carrera judicial y que accede por oposición.

Frente a este criterio, el trabajo de Hans Jürgen Brandt sobre la justicia de paz nos presenta una justicia de paz consolidada numéricamente frente a la letrada, con un gran nivel de aceptación por la confianza que genera en sus usuarios. Es una justicia que se ha mantenido y ha sobrevivido en el tiempo, y que hoy se confronta como un modelo de legitimidad y confianza en la administración de justicia.

El desarrollo histórico normativo de la justicia de paz nos lleva a resaltar dos ideas fundamentales: la justicia de paz, pese al tiempo transcurrido, no ha desaparecido ni se ha debilitado; todo lo contrario: es una institución en plena vigencia y con gran proyección hacia su crecimiento y fortalecimiento.

La justicia de paz ha sobrevivido, con sus propios matices, en su peculiar espacio, que dista de la justicia letrada, sin que esta haya logrado avasallarla o aniquilarla. Por eso, coincidimos con Silvia Loli ${ }^{12}$ cuando señala que "la supervivencia de la institución fue posible porque la justicia de paz había sido considerada integrante de los municipios y del Poder Judicial a la vez. La poca claridad sobre su ubicación en el nuevo

11 PUENTES DEL BARRIO, Luis. Juzgados de paz en la costa norte del Perú. Lima: Diaconía para la Justicia y la Paz, 1997, p. 37.

12 LOLI ESPINOZA, Silvia. "La justicia de paz en el Perú", en Acceso a la justicia. Lima: Oficina Técnica de Proyectos de Cooperación Internacional del Poder Judicial, 1997, p. 85. 
orden de cosas que se venía gestando permitió que, desaparecido uno de los espacios de referencia, el otro le sirviera como soporte".

El mimetismo de esta justicia, para su sobrevivencia, no podemos atribuirlo a acuerdos formales sobre su ubicación y consolidación como medio de solución de conflictos; todo lo contrario: es fruto del tiempo y de sus circunstancias, a los que ha tenido que asumir y enfrentar como su mejor aliado para poder emerger, igual que hoy, como la justicia de acceso inmediato y de rápidos resultados.

\section{Características de la justicia de paz}

La justicia de paz constituye uno de los estamentos de la organización judicial orientada a resolver los conflictos mediante la jurisdicción. Entendemos por jurisdicción a la función pública que tiene por objeto resolver las controversias jurídicas que se plantean entre dos partes contrapuestas y que deben someterse al conocimiento de un órgano del Estado, el cual decide dichas controversias de manera imperativa e imparcial.

Entre las principales características que convergen en la justicia de paz están las siguientes:

\subsection{Justicia consuetudinaria}

Uno de los referentes que se maneja en la justicia de paz para solucionar los conflictos es la costumbre. Ella constituye una norma de derecho cuyo valor jurídico reposa en la tradición y en su cumplimiento constante y uniforme a través del tiempo, con la misma fuerza de la ley. La costumbre, como la ley, constituye también fuente del derecho. No es de uso exclusivo de la justicia de paz; todo lo contrario: se extiende a otras manifestaciones, como la actividad comercial. La Constitución ha regulado la costumbre como referente para la justicia comunal nativa y campesina, siempre y cuando no atente contra los derechos fundamentales de la persona (entiéndase, el derecho a la vida, a la libertad, por citar algunos). Como la costumbre se asienta en un derecho no escrito, es necesario destacar ciertos parámetros que permitan descifrar cuándo estamos ante ella. La constancia del comportamiento, la convicción de su obligatoriedad y la no alteración de los principios fundamentales del ordenamiento jurídico de donde emerge son, pues, elementos constitutivos de ella. 
La costumbre es el referente en preferencia sobre el que descansan las soluciones logradas en la justicia de paz. La escasa preparación jurídica del juez implica el desconocimiento de la ley, lo que hace que se incline por soluciones basadas en usos y costumbres de su entorno, contribuyendo con ello a construir un auténtico derecho consuetudinario nacional. En esta misma lógica se orienta la Ley Orgánica del Poder Judicial cuando señala que "los jueces de paz preservan los valores que la Constitución consagra, respetan la cultura y las costumbres del lugar"..$^{13}$

\subsection{Justicia lega}

La justicia de paz es ejercida por personas que no requieren de preparación jurídica; basta que sepan leer y escribir, y en algunos casos se les exige haber cursado - cuando menos - instrucción primaria completa. Ello es comprensible porque la solución que van a dar a los conflictos no necesariamente va a tener como referente a la ley, sino a los usos y costumbres del lugar. Es más, la ley orgánica permite que los jueces de paz pronuncien sentencia según su leal saber y entender, no siendo obligatoria su fundamentación jurídica. La condición de juez no letrado se contrapone a los jueces técnicos jurídicos que operan también en la administración de justicia, lo que nos lleva a decir que en el Perú coexiste un sistema dual de judicatura: la letrada y la lega. Ello no es un fenómeno propio de nuestro país, sino que es una expresión del mundo de hoy: la confrontación entre la justicia técnica y la justicia popular.

Se dice que los jueces que se ubican en esta última modalidad olvidan que el buen desempeño del oficio judicial exige delicadas condiciones de formación jurídica, sociológica y, sobre todo, independencia frente a los grupos que lo proponen o eligen. Sin embargo, en nuestro país, diversos estudios de campo disienten de aquello, pues sitúan a la justicia de paz dentro de un margen de gran aceptación porque obtiene soluciones rápidas, satisfactorias y confiables, aceptación que no se

${ }_{13}$ Art. 66 de la LOPJ. 
extiende a los jueces letrados, ${ }^{14}$ para quienes Castán ${ }^{15}$ hace notar que "la función judicial requiere juicio objetivo e imparcial sin consideración de personas, clara visión de los hechos, conocimiento seguro de los hombres, entereza respecto del superior, benevolencia para con el inferior (...) en definitiva, de la colectividad o aun de la misma humanidad eliminando toda influencia partidista".

En la actualidad, en Europa existe la tendencia al reconocimiento de la independencia en la función judicial y hacia el régimen de profesionalización en la justicia de paz, situación que al parecer se contrapone con nuestra realidad nacional, donde cerca del $80 \%$ de jueces no son profesionales. ${ }^{16}$

\subsection{Justicia popular}

Calificamos a la justicia de paz como popular debido a la naturaleza de los conflictos que ventila, al acceso inmediato de los pobladores a aquella y a los resultados que obtienen de ello. En efecto, en los conflictos que ventila destaca un elemento común: su escasa significación social. Esto lo ha comprendido el derecho al asignarle a la justicia de paz la competencia del tratamiento de estos conflictos, cuya naturaleza no reviste mayor gravedad - aparte de su reducido valor monetario-, como sí la tiene la comisión de ilícitos penales, motivo por el cual ha derivado su tratamiento a la justicia local. Por otro lado, contribuye al carácter popular su fácil acceso: el juez de paz se ubica geográficamente en el entorno de la población, en la mayoría de los casos es un poblador conocido en la zona, lo que permite que su interrelación con las par-

14 Véase, en este sentido, el trabajo de BRANDT, Hans Jürgen. En nombre de la paz comunal: un análisis de la justicia de paz en el Perú. Lima: Fundacion Friedrich Naumann/ Centro de Investigaciones Judiciales de la Corte Suprema de Justica de la República, 1990; realizado en 1987 en las tres regiones del país.

15 CASTÁN TOBEÑAS, José. Poder judicial e independencia judicial. Madrid: Instituto Editorial Reus, 1951, p. 39.

16 Según la Comisión Andina de Juristas, a diciembre de 1998, en el ámbito nacional existían 3.699 jueces de paz. COMISIÓN ANDINA DE JURISTAS. Gente que hace justicia. Lima: CAJ, 1999, p. 233. 
tes en conflicto sea de mayor confianza y familiaridad. Esto hace que los criterios de solución manejados se ajusten a lo consuetudinario del entorno, lo que genera una mayor satisfacción en el resultado logrado. También la justicia de paz facilita una solución rápida a los problemas de las partes, quienes en la mayoría de los casos son protagonistas de sus soluciones, pues tienden a privilegiar el acuerdo como mecanismo de solución. Por último, hay una marcada preferencia por recurrir a este tipo de justicia, lo que refuerza su carácter popular: su fácil acceso, debido a la cercanía geográfica; el bajo costo que implica litigar en ella y el logro de soluciones rápidas, genera un clima de confianza en la justicia de paz.

\section{Los mecanismos para la designación de jueces}

La función primordial de los jueces de paz siempre ha sido la actividad conciliatoria. En sus inicios, el oficio lo desempeñaba el alcalde, quien era nombrado por elección; la Constitución de Cádiz de 1812, que rigió la vida nacional hasta 1814 , así lo estableció. ${ }^{17}$ Este mecanismo de elección popular se recogió, no solo en el Reglamento provisional de tribunales y juzgados de 1822, sino en la Constitución de 1823. El reglamento establecía que en la capital de los departamentos del Estado debía existir un juez de alzada letrado, elegido por el pueblo, como los individuos de la municipalidad, y la Constitución de 1823 disponía que "los alcaldes son los jueces de paz de su respectiva población". Para ser elegido se requería tener 25 años de edad y ser natural del pueblo o tener diez años de vecindad antes de la elección, entre otros requisitos. ${ }^{18}$ Estos requisitos se mantienen, aunque con algunas variaciones: ser mayor de 30 años; ser vecino del lugar donde se ha de ejercer el cargo; haber cursado por lo menos primaria completa; tener profesión u oficio conocidos; y conocer, además del castellano, el quechua, el aimara o cualquier otro dialecto, si en el lugar donde se va a actuar predomina uno de ellos. ${ }^{19}$

\footnotetext{
17 Art. 282 de la Constitución de Cádiz de 1812.

18 Arts. 142 y 144 de la Constitución de 1823.

19 Art. 183 de la LOPJ de 1993.
} 
En 1834 se crearon las primeras juntas municipales, asumiendo los alcaldes las funciones de jueces de paz, además de poder hacerlo también los regidores y notables. Para obtener el cargo, no solo se requería ser ciudadano en ejercicio, sino también tener una propiedad raíz y pagar contribuciones, situación que desde ya nos muestra el nivel económico que debía gozar quien pretendiera ejercerlo.

Al dejar de existir las juntas municipales - a las que pertenecían los jueces de paz-, el presidente Riva Agüero decretó en 1838 que en todas las provincias los subprefectos propusieran en terna al prefecto del departamento los individuos que debían desempeñar el cargo de juez de paz en las poblaciones de su dependencia..$^{20}$ El criterio poblacional que se había tomado como referente para asignar un número de jueces se abandonó, y se optó por nombrar dos jueces de paz en cada distrito, exceptuándose aquellos que a juicio del prefecto tuviesen muy corta población, en los cuales había uno solo.

Las municipalidades, luego de elegir a los jueces de paz, comunicaban a los subprefectos y estos a los prefectos las listas de los jueces elegidos cada año, para que se publiquen en los periódicos. Sin perjuicio de ello, las listas se fijaban en los parajes públicos de los respectivos distritos.

Como ya se ha señalado, la condición patrimonial constituía requisito básico para ser juez de paz, criterio que se reforzó con el devenir de los años. En 1900, el presidente Eduardo de Romaña promulgó la Ley reformatoria de los juzgados de paz. En ella se establecía que las cortes superiores nombraran a los jueces de paz, mecanismo que se mantiene hasta la actualidad, con algunas variaciones no sustanciales.

El cargo de juez de paz recaía con preferencia en quienes tenían título profesional o eran propietarios de bienes raíces o ejercían alguna industria por la que pagasen alguna contribución al Estado. El nombramiento de los jueces por designación directa de la corte fue regulado también en la Ley Orgánica del Poder Judicial (en adelante, LOPJ) de

20 En la capital, los referidos jueces eran nombrados por el gobierno, a propuesta, en terna, del prefecto (art. 2 del Decreto del 20 de noviembre de 1838). 
1911. La corte nombraba a los jueces de paz de entre los propuestos por los jueces de primera instancia. ${ }^{21}$

En 1924, el presidente Leguía promulgó la Ley 4871, disponiendo que la administración de justicia de menor cuantía fuese ejercida en Lima por dos jueces de paz letrados, elegidos por la corte superior a propuesta, en terna, de los jueces de primera instancia. Estos jueces sí percibían un haber mensual, despachaban días hábiles y no podían ser reelectos sino una sola vez.

La LOPJ de 1963 continuó con el sistema de nombramiento por la corte superior, cada año, teniendo preferencia para desempeñar el cargo de juez de paz los letrados que figuren en las ternas. Este criterio también es recogido por la actual LOPJ de manera más amplia, pues incorpora a los titulados, egresados y estudiantes de derecho.

Los jueces de primera instancia formulaban las ternas simples para la designación de los jueces de paz, y los acuerdos se tomaban por mayoría de votos. Es recién con la LOPJ de 1963 que se regula el procedimiento para el nombramiento de jueces de paz. La formación de ternas y la elección de cargos judiciales se realizaban por votación mediante cédula y por mayoría de votos. Si nadie la obtenía, se procedía a segunda votación entre los dos que hubiesen alcanzado mayor número de votos, decidiendo la suerte en caso de empate. ${ }^{22}$

Los jueces de primera instancia de una misma provincia se reunían en junta, presididos por el decano, para formular las ternas simples destinadas a la designación de los jueces de paz de su jurisdicción. Los acuerdos se tomaban por mayoría de votos, de lo que se dejaba constancia en un libro especial. Comentando el mecanismo de elección por ternas, Carlos Giusti ${ }^{23}$ manifestaba su preocupación porque estas se conformaban teniendo en cuenta las gestiones que realizaban los interesados en ser beneficiados con el nombramiento, quienes no siempre desempeñaban una labor en beneficio de la comunidad.

${ }^{21} \quad$ Inciso 8 del art. 93 de la LOPJ de 1911.

22 Art. 54 de la LOPJ de 1963.

23 GIUSTI, Carlos. "Un poder cercado", en Temas peruanos: la justicia de paz y el pueblo. Lima: Centro de Investigaciones Judiciales de la Corte Suprema/ Fundación Friedrich Naumann, 1987, p. 128. 
La elección del juez de paz también comprendía la del accesitario, quien asumía funciones por ausencia, enfermedad, suspensión o muerte de aquel. El Reglamento de Jueces de Paz de 1854 regulaba su elección, como también lo hace la actual LOPJ: "Conjuntamente con la designación se debe establecer como accesitarios de su terna a los candidatos que por su orden suplen al titular en caso de vacancia, impedimento o ausencia". ${ }^{24}$

Históricamente, los jueces de paz eran elegidos por un periodo que oscilaba entre uno y dos años. Para la Constitución de Cádiz el oficio duraba un año; para la Constitución de 1826 los alcaldes y jueces de paz se renovaban cada dos años y podían ser reelegidos. La Ley Orgánica de Municipalidades de 1834 consideró en un año la duración del cargo de juez de paz. Los reglamentos de jueces de paz dispusieron la duración del cargo en un año. ${ }^{25}$ Posteriormente, la LOPJ de 1963 estableció que los jueces fuesen nombrados cada año por la corte superior respectiva, pudiendo ser reelegidos hasta dos veces.

En 1986 se concluye la redacción del proyecto Alzamora Valdez, sobre la LOPJ, que recomendaba la elección popular de los jueces de paz mediante el siguiente mecanismo: ${ }^{26}$

El juez de paz será elegido para un período de tres años en el mes de octubre, por los ciudadanos residentes dentro de la jurisdicción territorial de cada juzgado de paz. Se eligen tres candidatos que forman una terna simple. Concluido el sufragio, las ternas que contienen los datos personales, en relación a los requerimientos del cargo, así como los resultados de la elección, son remitidos por los jueces de primera

$24 \quad$ Art. 69 de la LPOJ de 1993.

25 Este reglamento contempló que nadie podía excusarse de admitirlo. Sin embargo, la Ley 1900 fue más drástica, pues dispuso que la persona que sin causa legal se niegue a desempeñar el cargo pagará una multa de 100 a 300 soles al respectivo concejo.

26 Art. 232 del proyecto redactado por Mario Alzamora Valdez, Manuel Catacora, Hugo Manchego, Octavio Linares y Javier de Belaunde, el que fue concluido en 1986. 
instancia al Consejo Distrital de Gobierno, el cual nombra a aquel candidato que recibió la mayoría relativa de votos. En caso que este candidato no cumpliera con los requerimientos, establecidos para el cargo, se nombra al siguiente candidato de la terna y si éste tampoco cumple con los requerimientos, al tercero. Los jueces de paz no pueden ser reelegidos para el período inmediato.

La modalidad de incorporación de jueces que planteaba el proyecto no fue acogida y se mantuvo el tradicional sistema de designación, el que fue replanteado recién con la promulgación de la Constitución de 1993.

Como se ha dicho, la redacción de la LOPJ de 1993 no contiene aportes sustanciales para la incorporación de los jueces. Se mantiene el viejo esquema del appointment, que permite que los jueces de paz sean designados por el órgano de gobierno, consejo ejecutivo distrital, por un periodo de dos años. Para la designación se deben tener en cuenta las propuestas de los concejos municipales distritales, concejos municipales menores, comunidades campesinas, comunidades nativas, parcialidades, agencias municipales y sectores representativos que lo requieran. Tratándose de comunidades campesinas, la asamblea general tiene la atribución de proponer candidatos para el nombramiento de los jueces de paz. ${ }^{27}$

A este mecanismo de designación que regula la LOPJ (artículo 69) se contrapone el que consagra el artículo 152 de la Constitución, referente a la elección popular de los jueces de paz.

A pesar de que la propia Constitución señala que dicha elección será normada por ley, esta no ha llegado a promulgarse, lo que ha motivado que la Comisión Ejecutiva del Poder Judicial - que asumió el gobierno de la institución judicial-, mediante cuestionables resoluciones administrativas, haya regulado la aplicación de la norma constitucional. ${ }^{28}$

Ante este impasse legislativo, el Consejo Ejecutivo del Poder Judicial dispuso por Resolución Administrativa ${ }^{29}$ 102-2001-CE-PJ, que en tanto

\footnotetext{
$27 \quad$ Ley 24656.

28 Resolución Administrativa 844-CME-PJ.

29 Publicada en el diario oficial El Peruano el 8 de setiembre del 2001.
} 
se expida la ley que desarrolle el mandato del artículo 152 de la Constitución, la designación de jueces de paz, cuando se hubiere vencido su periodo de nombramiento, se ajuste a lo previsto en el artículo 69 de la LOPJ, esto es, que sean elegidos por el respectivo consejo ejecutivo distrital o, en caso de no existir este, por la sala plena de cada corte superior. ${ }^{30}$

En los últimos tiempos, muchos han venido proponiendo la elección popular del juez de paz, y hay quienes se han sumado a la expectativa que ha generado la regulación del artículo 152 de la Constitución de 1993. Hoy, esas aspiraciones se encuentran en sustancia contempladas en la Ley 27539, que regula la elección popular del juez de paz, ${ }^{31}$ luego modificada por la Ley 28545, publicada en junio del 2005.

\section{Requisitos formales para ser juez de paz}

\subsection{Edad}

Entendida como la dimensión temporal de la vida de un ser, como el tiempo que ha vivido la persona a partir de su nacimiento, la edad tiene especial relevancia para el derecho, pues permite establecer la capacidad de la persona. Existe una edad básica, fijada en los 18 años, que determina jurídicamente la plena capacidad de ejercicio e independencia del sujeto.

$30 \quad$ Inc. 1 del art. 94 de la citada ley orgánica.

31 "Nos atrevemos a sugerir la conveniencia de sustituir el actual procedimiento por el de elecciones generales realizadas cada tres años, conjuntamente con la elección de alcaldes, para que los distritos de la República puedan elegir a los jueces no letrados de su respectivo centro poblado" (GIUSTI, Carlos, Op. cit., p. 128). "Para fortalecer todavía más los vínculos entre los jueces de paz y la comunidad y para reforzar el control social sobre el desempeño del cargo proponemos la elección del juez de paz" (BRANDT, Hans-Jürgen. Op. cit., p. 404). Véase también DE BELAUNDE, Javier. “Elección popular de jueces", en La Constitución de 1993: análisis y comentarios. Serie Lecturas sobre temas constitucionales 10. Lima: Comisión Andina de Juristas, 1994, pp. 203-217. 
La edad también es un requisito para ejercer la función judicial. La LOPJ establece que para ser juez de paz se requiere ser mayor de 30 años. La derogada Ley 27539 y la vigente 28545, que regula la elección de jueces de paz, exigen que los candidatos sean mayores de 25 años. Estudios publicados al respecto, como el de Silvia Loli, ${ }^{32}$ consideran esa edad como arbitraria, pues según nuestras leyes la ciudadanía se obtiene a los 18 años.

Hay una tendencia a construir un modelo de juez joven, que rompe con el criterio de asociar la edad con la sabiduría. Sin embargo, por sí sola, la edad no podría ser un buen referente para modelo de juez si no va asociada con conocimientos técnico-jurídicos, por lo que se tiende a compensar la poca experiencia de vida con una mayor preparación técnica, propia de los estudios universitarios. En esa línea se ubica el anteproyecto de justicia de paz de 1974, presentado por Chunga, ${ }^{33}$ cuando dice que "el estudiante universitario inicia su formación profesional alrededor de los 17 años de edad y la culmina alrededor de los $25^{\prime \prime}$, para justificar la corta edad en los jueces de paz. Se puede advertir que hay una clara opción por rebajar la edad de los jueces para no excluir a los abogados jóvenes de la posibilidad de ocupar dichos cargos.

Se puede percibir que en los jueces de Lima la edad varía sustancialmente según la zona de ubicación. Los jueces de los balnearios de Lima tienen una edad que está entre 25 y 35 años, mientras que la edad de los jueces de las zonas rurales está entre 45 y 55 años. Esta evidencia refleja líneas de pensamiento ya trabajadas en estudios de campo. En 1981, la Fundación Ford publicaba que la edad de la mayor parte de los jueces de las zonas rurales se ubica en 50 años o más. ${ }^{34} \mathrm{La}$ preferencia por esta edad de los jueces en esas zonas, es un criterio que hasta hoy se mantiene. En Lima se prefieren jueces de entre $45 \mathrm{y}$ 55 años para esas zonas, a diferencia de los jueces de balnearios, cuya edad es uniforme y no supera los 35 años. La tendencia a preferir en

32 Op. cit., p. 92.

33 Anteproyecto de justicia de paz, en Justicia de paz en el Perú. Lima, 1979, p. 285.

${ }_{34}$ "La justicia de paz no letrada en el Perú" (mimeo). Lima: Fundación Ford, 1981, citado en LOLI, Silvia. Op. cit., p. 92. 
las zonas rurales al juez de edad avanzada se explica por el valor social y cultural que se le asigna a la experiencia de vida. Se suele ligar sabiduría con edad porque así se genera equilibrio en las decisiones y, por ende, el respeto de los demás; sin embargo, en el caso particular de Lima se advierte que la edad en las zonas rurales no es homogénea, como sí lo es en las zonas de balnearios. Se nota en las zonas rurales mayor permisibilidad para incorporar tanto jueces de edad avanzada como de menor edad. Esto podría explicarse por el efecto que genera el acceso de los pobladores a la educación superior y la cercanía geográfica al centralismo limeño, lo que corrobora la tesis de Silvia Loli, ${ }^{35}$ de que "la edad tiende a disminuir cuando el nivel de desarrollo del pueblo aumenta, teniendo los jueces además un mayor nivel de instrucción".

\subsection{Residencia}

La residencia, otro de los requisitos para ser juez de paz, la define Flores $\mathrm{Polo}^{36}$ como "el lugar donde una persona habita o tiene un asiento de sus negocios, sin que este sea necesariamente su domicilio".

Para la LOPJ, el juez de paz debe ser vecino del lugar donde ha de ejercer el cargo, ${ }^{37}$ pero la Ley 27539 exige de manera categórica, además, que sea residente en la circunscripción por mas de dos años. Así, la permanencia o estancia del residente en un lugar, supera el concepto de mera vecindad a que se refería la LOPJ.

La residencia responde a la necesidad de garantizar la presencia cotidiana de la autoridad, lo cual contribuye a que la justicia se torne más cercana y accesible al poblador. Permite afianzar la identidad cultural entre el juez y las partes, haciendo posible que ambos compartan usos, creencias, valores, ritos de la zona, todo bajo una misma cosmovisión del mundo. Como ya lo expresa Brandt, ${ }^{38}$

35 Op. cit., p. 93.

36 FLORES POLO, Pedro. Diccionario de términos jurídicos. Tomo II. Lima: Cusco Editores, 1980, p. 439.

${ }_{37}$ Inc. 2 del art. 183 de la LOPJ.

38 Op. cit., p. 105. 
... el juez de paz por ser vecino del lugar conoce de cerca la realidad socio-cultural y económica de su medio, conoce mejor a las partes en conflicto, en el caso de pueblos pequeños, y puede expresarse en el idioma nativo de las partes. Estos factores favorecen la concreción de un mecanismo de justicia equitativo, que toma en consideración los valores culturales de la zona, las diversas concepciones frente al conflicto, así como las posibles vías de solución que tiendan a satisfacer las aspiraciones de justicia de la población.

Todo lo expresado sobre la razón de ser de la residencia del juez se ve trastocado en Lima en lo que respecta a los jueces de balnearios, quienes no residen en la zona donde administran justicia, sino que concurren a ella, en promedio, tres veces a la semana. Ello hace que el juez de paz no sea conocido por los pobladores y que estos encuentren dificultades para acceder a la justicia debido a lo reducido y fijo de los horarios de aquel. En cuanto a los jueces de la zona rural, hay una fuerte tendencia a que residan en la localidad donde ejercen sus funciones.

\subsection{Instrucción}

El caudal de conocimientos adquiridos en el sistema escolar es un elemento requerido para ejercer de juez; tanto la LOPJ como la Ley 27539 exigen que el candidato a tal haya cursado por lo menos instrucción primaria completa. ${ }^{39}$ Estas normas son coherentes con la realidad de los pobladores de las zonas más alejadas del país: analfabetismo y baja escolaridad.

Coincidimos con Brandt cuando este último afirma que "el nivel de instrucción de los jueces de paz aparentemente ha mejorado." Pásara ${ }^{40}$ observaba que el 40,1\% de los jueces tenía instrucción primaria, el 27,5\% secundaria y el $30,5 \%$ superior. Brandt, ${ }^{41}$ por su parte, muestra que solo

39 Inc. 3 del art. 183 de la LOPJ y art. 8 de la Ley 27539.

40 PÁSARA, Luis. "La justicia de paz no letrada, diagnóstico" (mimeo). Estudio preparado por encargo del Consejo Latinoamericano de Derecho y Desarrollo, bajo convenio con la Corte Suprema de Justicia. Lima, 1979, p. 19, citado por Brandt. Op. cit., p. 107.

41 Ibíd. 
el $21,6 \%$ de los jueces tiene primaria o primaria incompleta, el $45,6 \%$ secundaria o secundaria incompleta y el 32,9\% instrucción superior. Analizando el grado de instrucción de los jueces según las zonas, Brandt encuentra diferencias notables: los jueces urbanos tienen un mayor grado de instrucción que los de medios rurales. En zonas rurales hay un mayor número de jueces con primaria $(27,7 \%)$, en tanto que en zonas urbanas es más frecuente encontrar jueces con instrucción superior $(43,1 \%)$.

Ledesma $^{42}$ considera que el nivel de instrucción de los jueces de paz en Lima ha variado sustancialmente en relación con lo que observaba Pásara, pues ha crecido la cantidad de jueces con estudios superiores. Además, corrobora lo expuesto por Brandt en cuanto al mayor nivel de instrucción de los jueces de las zonas urbanas, dado que la totalidad de los jueces de balnearios de Lima tiene estudios superiores. También aprecia una mejoría en el nivel de instrucción de los jueces de paz de las zonas rurales, pues todos tienen estudios primarios, el 25\% secundarios y el 75\% estudios superiores. La mejora en la instrucción podría explicarse por la ampliación del sistema escolar, como señalaba Brandt, a lo que habría que agregar, para el caso de los juzgados de paz de Lima, la cercanía de los poblados a la capital, donde se concentra el mayor número de instituciones académicas.

La situación del nivel de instrucción de los jueces de paz responde a la tendencia de que los cargos judiciales sean ocupados preferentemente por titulados, egresados y estudiantes de derecho, sin que ello signifique que por ser los más capacitados, sean los que mejor ejerzan la función de juez. ${ }^{43}$ Del estudio de casos de Ledesma, ${ }^{44}$ tanto en los juzgados urbanos como en los rurales de Lima, se advierte que son estos últimos los que más casos solucionaron, sobre todo por conciliación, destacando el Juzgado de Ricardo Palma. En cambio, los jueces de balnearios tuvieron un significativo número de causas pendientes de resolver, como el Juzgado de Punta Negra, y un reducido número de conciliacio-

42 LEDESMA, Marianella. La justicia de paz en Lima. Lima: Fondo Editorial de la Universidad Inca Garcilaso de la Vega, 2002, p. 81.

43 Art. 69 de la LOPJ.

44 LEDESMA. Op. cit., pp. 81-82. 
nes. Este comportamiento de los juzgados de Lima corrobora la tendencia ya señalada por Brandt ${ }^{45}$ de que a mayores niveles de escolaridad la tasa de causas conciliadas o arregladas baja, mientras que el porcentaje de causas pendientes tiende a subir.

Por otro lado, en el país hay estudios relacionados con el nivel de instrucción de las mujeres, que determinan que son ellas quienes sufren la mayor tasa de analfabetismo, lo que explicaría la existencia de un reducido número de juezas de paz. ${ }^{46}$ Sin embargo, en el estudio que realiza Ledesma $^{47}$ en los juzgados de paz de Lima, dicha apreciación presenta variaciones: los juzgados de paz de balnearios son desempeñados por juezas en su totalidad, aunque lo mismo no sucede en los juzgados de las zonas rurales, donde hay una marcada presencia de jueces, con excepción del poblado de San José de Pallé, donde no solo administraba justicia una mujer, sino que los cargos de agente municipal y alcalde estaban desempeñados también por mujeres.

\subsection{Ocupación}

El desempeño de un empleo o de una tarea habitual es condición necesaria para ejercer la judicatura de paz, al objeto de impedir que se usufructúe del cargo, máxime si se trata de una labor ad honorem. ${ }^{48}$

Los jueces de paz tienen por lo general la ocupación de abogado, profesor jubilado o agricultor. Todos los jueces de la zona de balnearios son abogados, a diferencia de los de la zona rural, que en su mayoría son profesores jubilados. El ejercicio simultáneo de la abogacía y la judicatura está prohibido en la justicia letrada, lo que no sucede con los jueces legos debido a que no son rentados por el Estado. Las diversas leyes orgánicas que han regulado la vida del Poder Judicial no han dejado de enunciar la posibilidad de que los jueces de paz ejerzan simultáneamente la abogacía. ${ }^{49}$

45 Op. cit., p. 110.

46 Véanse los estudios de Brandt y Loli. Op. cit., p. 95.

${ }^{47}$ Ibíd.

48 El Estado, para efectos pensionables, solo reconoce el tiempo de ejercicio como juez de paz. Ver el art. 69 de la LOPJ y la disposición segunda, transitoria y final de la Ley 27539.

49 Inc. 1 del art. 312 de la LOPJ de 1963. 


\section{Deberes, derechos y prohibiciones}

Como se ha señalado, la actividad de los jueces de paz en sus inicios fue ejercida por el alcalde del pueblo; incluso en algunos casos se permitía a los regidores y notables ejercer dicha función. Si bien la Ley Orgánica de Municipalidades de 1834 legisló las facultades de la autoridad municipal en la administración de justicia, también se preocupó de señalar que "ningún municipal ni notable podía exigir en su pueblo o provincia servicio alguno personal bajo ningún pretexto". Las atribuciones de los jueces de paz se orientaban, en ese contexto, a reclamar las resoluciones de la municipalidad que estuvieran en oposición con los intereses de los pueblos, a cuidar el ornato, recreo y los fondos municipales, a fomentar la industria, agricultura y minería, a velar por la instrucción primaria, a velar por la policía de las cárceles y los establecimientos de beneficencia, a reparar puentes, caminos y calzadas, a cuidar de la policía de los mercados para que no haya fraude en pesos y medidas, a dirigir representaciones al Congreso sobre las infracciones a la Constitución. ${ }^{50}$ Como se aprecia, la actividad del juez de paz no era exclusivamente jurisdiccional, sino que se involucraba en funciones netamente municipales, cosa explicable porque el alcalde del pueblo ejercía la función de juez de paz. Esta ancestral conducta aparece todavía reproducida en algunos jueces, sobre todo del área rural de nuestro estudio, como es el caso del poblado de San José de Pallé, ya citado.

La LOPJ de 1963, a diferencia de la de 1911, intentó regular diversos aspectos relacionados con la justicia de paz. En ella se asigna una serie de atribuciones de orden administrativo y jurisdiccional; en correlato, también se regula una serie de obligaciones y deberes para los jueces.

Entre las principales atribuciones de orden disciplinario estaba la potestad de sancionar y remover a los alguaciles y testigos actuarios. En cuanto a lo administrativo, los jueces estaban facultados para nombrar a sus alguaciles y testigos de actuación, así como para conceder licencia, por causa justificada, hasta por 15 días, al secretario y el personal del juzgado. La facultad de designar testigo actuario ha sido trasladada al

50 Ver lo regulado en los arts. 14 y 19 de la Ley Orgánica de Municipalidades de 1834. 
juez especializado, quien lo designa a propuesta en terna del juez de paz. ${ }^{51}$ Frente a estas atribuciones concurría la obligación de remitir trimestralmente a la corte, por intermedio del juez decano de la provincia, los datos necesarios para la estadística judicial. También estaban obligados - al tomar posesión del cargo - a realizar un inventario, y en todo caso cada dos años, de los libros, expedientes archivados y demás enseres del juzgado, que también se remitían a la corte.

Los jueces de paz estaban obligados a instruir en casos de reincidencia y vagancia, ${ }^{52}$ ya derogadas, a formar el consejo de familia, a ordenar la actuación de diligencias preparatorias (hoy llamada prueba anticipada) para el reconocimiento de instrumentos privados, absolución de posiciones en pliego abierto, inspección ocular destinada a acreditar daños y perjuicios o hechos que pueden desaparecer o cambiar.

En los lugares donde no había jueces de primera instancia, los jueces de paz estaban obligados a visitar las cárceles el último sábado de cada mes, llevando un libro de visita y dando cuenta mensualmente, a los de primera instancia, del número de presos o detenidos que existiesen en las cárceles de los pueblos distantes de la capital, con expresión de las causas, motivos o delitos por los que se hallasen en ellas. Esta obligación, que inicialmente fue recogida por el Reglamento de justicia de paz de 1939, fue mantenida en el reglamento de 1854 y en la Ley Orgánica de 1911. Esta última no solo le encargó al juez de paz ejercer las atribuciones administrativas que tenían los jueces de primera instancia, sino también le asignó el inicio de los sumarios penales, la remisión de los procesos criminales y civiles al juez que correspondiese, así como informar de las causas que estaban pendientes de la intervención del juez, y la relación de abogados del lugar..$^{53}$

$51 \quad$ Art. 71 de la LPOJ de 1993.

52 En relación con la vagancia, la Corte Suprema emitió la resolución del 30 de diciembre de 1971, donde señalaba que los jueces que instruyen por vagancia reiterante están facultados para poner en libertad incondicional a los detenidos cuya condición presunta de vagos reiterantes no se ha comprobado, sin perjuicio de elevar la instrucción al superior inmediato (Anales Judiciales, 1971, p. 352).

53 Arts. 121 y 224 de la LOPJ de 1911. 
En cuanto a las prohibiciones, puede señalarse que el reglamento de $1839^{54}$ no les permitía a los jueces de paz detener ni encarcelar a persona alguna por demanda civil o deuda particular cuyo valor no pasase de seis pesos, debiendo en estos casos ordenar la satisfacción con el producto del trabajo del deudor o con el de las prendas que se le mandasen extraer. Esta prohibición no comprendía las deudas fiscales o de contribución de cualquier género en las que no tenían intervención los jueces de paz.

Por otro lado, en la actividad conciliatoria propia de estos jueces, están prohibidos de imponer acuerdos a las partes. Tampoco pueden conciliar y fallar en asuntos relativos a vínculo matrimonial, nulidad y anulabilidad de los actos jurídicos o contratos, sucesión intestada, derechos sucesorios, testamentos y derechos constitucionales y demás que les señale la ley. ${ }^{55} \mathrm{La}$ actual LOPJ considera que es abono el tiempo de ejercicio de los jueces de paz, para efectos pensionables. Asimismo, tienen derecho a percibir el abono de un monto fijado por el consejo distrital cuando realicen actuaciones fuera del despacho judicial.

\section{La insignia del juez de paz}

Desde los inicios de la actividad judicial, las insignias no solo fueron una señal o distintivo, sino también una divisa honorífica, utilizada por los miembros de la organización en los actos oficiales.

Si bien el Reglamento de Jueces de Paz de 1854 no se refiere a ellas, el Reglamento de Tribunales de 1854 sí regulaba el tratamiento, vestuario y distintivos que correspondían a los magistrados de las diversas instancias, aunque guardaba silencio en lo que a los jueces de paz se refiere, criterio que se reprodujo en la LOPJ de 1911.

Posteriormente, la LPOJ de 1963 estableció que el uso de las insignias de los jueces debía ser reglamentado por la Corte Suprema. Por Decreto Ley 18919 se dispuso que los jueces de paz letrados usarán medalla, pero pendiente de una cinta blanca en la solapa izquierda.

${ }^{54}$ Art. 41 del Reglamento de 1839.

55 Art. 67 de la LOPJ de 1993. 
La LOPJ de $1993^{56}$ permite al juez de paz, por primera vez, usar la misma medalla que usan todos los jueces, pero con la distinción de color plata y con la cinta blanca, pendiente en la solapa izquierda. La medalla tiene forma elíptica, es de cinco centímetros en su diámetro mayor, y cuenta con la figura de la justicia a medio relieve.

Lo expuesto permite pensar que las insignias no solo eran utilizadas como medios distintivos de los miembros de la organización judicial, sino también como una función honorífica que las jerarquías superiores no estaban dispuestas a compartir con los jueces de menor nivel jerárquico, mas aún si estos no eran letrados.

El actual componente de la judicatura letrada y el nuevo contexto en el que se desarrolla han permitido reconocer, aunque sea a media voz, que la justicia de paz también es una fuerte e importante integrante de la administración de justicia.

\section{El personal auxiliar y el juez de paz}

El juez de paz requiere ser asistido por auxiliares cuando administra justicia. Parte de ellos son los secretarios - antes denominados escribanos- y los alguaciles, estos últimos, llamados a cuidar el orden administrativo en el juzgado y a comunicar las citaciones del juez a los comparecientes.

Como se ha dicho, el inicio de la justicia de paz está marcado por una fuerte presencia de la autoridad municipal, lo que también se va a percibir en la designación del personal de los juzgados de paz.

Así, la Ley Orgánica de Municipalidades de $1834^{57}$ consideraba que "el secretario debía ser elegido de fuera, por votación y pluralidad absoluta".

Como los alguaciles ${ }^{58}$ eran rentados por las municipalidades, solo estas estaban facultadas para reemplazarlos; el juez no podía destituir al

$56 \quad$ Art. 234.

57 Art. 18.

${ }_{58}$ Los alguaciles tenían como obligación hacer las citaciones por cédulas para los comparendos. 
alguacil sin previo conocimiento del alcalde, quién accedía a ello si lo encontraba justo o conveniente luego de indagar verbalmente sobre los hechos. Cuando el alguacil no cumplía con su deber, la parte no se quejaba ante el juez, sino ante el alcalde, quien previo informe del juez de paz, de que el alguacil no cumplió con su deber, procedía a su remoción.

La influencia de la autoridad municipal sobre la designación del personal se mantuvo y se fue fortaleciendo. La Ley de Reforma de los Juzgados de Paz de $1900^{59}$ continuó considerando que "los amanuenses y los alguaciles de los juzgados de paz sean nombrados por el respectivo concejo provincial o de distrito, no pudiendo servir en más de un juzgado la misma persona". Estos amanuenses desempeñaban el cargo durante un año y podían ser reelegidos.

Recién en 1924, por Ley 4871, se dispone que el servicio de cada juzgado sea atendido por un escribano de estado, designado por la corte superior, y un alguacil, nombrado por el juez, con un haber mensual para cada uno de ellos. Esta ley rompe con el viejo esquema de que sean los concejos provinciales y de distrito los que señalen y abonen el haber de los amanuenses. Bajo esa misma influencia, el alguacil gozaba también de un sueldo, pero fijado y pagado por el concejo que lo nombró. ${ }^{60}$ Como una atribución administrativa, la LOPJ de 1963 facultaba a los jueces a nombrar sus alguaciles y testigos de actuación, jueces que asimismo tenían la potestad de conceder licencia por causa justificada, hasta por 15 días, al secretario y el personal del juzgado. En la actualidad, la facultad para designar al testigo actuario del juzgado de paz ha sido trasladada al juez especializado, quien lo designa a propuesta en terna del juez de paz. ${ }^{61}$

\section{Conclusiones}

1. La justicia de paz ha estado vinculada desde sus inicios con la actividad que realizaban los alcaldes. Con las primeras juntas municipa-

\footnotetext{
59 Art. 2.

60 Art. 2 de la Ley de reforma de 1900.

${ }^{61}$ Art. 71 de la LPOJ de 1993.
} 
les, los alcaldes también asumieron las funciones de los jueces de paz y eran designados por elección.

2. El juez de paz asume un rol, sobre todo, conciliador; de ahí su nombre: juez de avenimiento o juez de la paz. Desde la Constitución de Cádiz de 1812, el juez de paz interviene como conciliador, antes de la interposición de la demanda, función que desarrolla hasta la fecha, pero con ciertas limitaciones.

3. La justicia de paz es una justicia con rasgos particulares, que la distinguen de la justicia oficial, como los de ser consuetudinaria, lega y popular.

4. El juez de paz ejerce función jurisdiccional, pero no está comprendido dentro de la carrera judicial. Su permanencia, elección y condiciones para desempeñar el cargo están expresamente señaladas en la ley de la materia. 


\section{Bibliografía}

"Anteproyecto de justicia de paz", en Justicia de Paz en el Perú. Lima, 1979.

CASTÁN TOBEÑAS, José. Poder judicial e independencia judicial. Madrid: Instituto Editorial Reus, 1951.

Constitución de Cádiz de 1812.

Constitución peruana de 1823.

Constitución peruana de 1826.

Constitución peruana de 1828.

Constitución peruana de 1993.

Decreto del 20 de noviembre de 1838.

FLORES POLO, Pedro. Diccionario de términos jurídicos. Tomo II. Lima: Cusco Editores, 1980.

GIUSTI, Carlos. "Un poder cercado", en Temas peruanos: la justicia de paz y el pueblo. Lima: Centro de Investigaciones Judiciales de la Corte Suprema/ Fundación Friedrich Naumann, 1987.

LEDESMA, Marianella. La justicia de paz en Lima. Lima: Fondo Editorial de la Universidad Inca Garcilaso de la Vega, 2002.

Ley Orgánica de Municipalidades de 1834.

Ley Orgánica del Poder Judicial (LOPJ).

Ley 1900.

Ley 24656.

Ley 27539.

LOPJ de 1911.

LOPJ de 1963.

LOPJ de 1993.

LOLI ESPINOZA, Silvia. "La justicia de paz en el Perú", en Acceso a la justicia. Lima: Oficina Técnica de Proyectos de Cooperación Internacional del Poder Judicial, 1997.

PÁSARA, Luis. "La justicia de paz no letrada, diagnóstico" (mimeo). Estudio preparado por encargo del Consejo Latinoamericano de 
Derecho y Desarrollo, bajo convenio con la Corte Suprema de Justicia. Lima, 1979.

PUENTES DEL BARRIO, Luis. Juzgados de paz en la costa norte del Perú. Lima: Diaconía para la Justicia y la Paz, 1997.

Reglamento de 1839.

Reglamento de 1854.

Resolución Administrativa 844-CME-PJ. 